This item was submitted to Loughborough's Research Repository by the author.

Items in Figshare are protected by copyright, with all rights reserved, unless otherwise indicated.

\title{
Effect of dispersants on the rheology of aqueous silicon carbide suspensions
}

PLEASE CITE THE PUBLISHED VERSION

PUBLISHER

(C) Elsevier

LICENCE

CC BY-NC-ND 4.0

REPOSITORY RECORD

Zhang, Yongheng, and J.G.P. Binner. 2008. "Effect of Dispersants on the Rheology of Aqueous Silicon Carbide Suspensions". figshare. https://hdl.handle.net/2134/3455. 
This item was submitted to Loughborough's Institutional Repository by the author and is made available under the following Creative Commons Licence conditions.

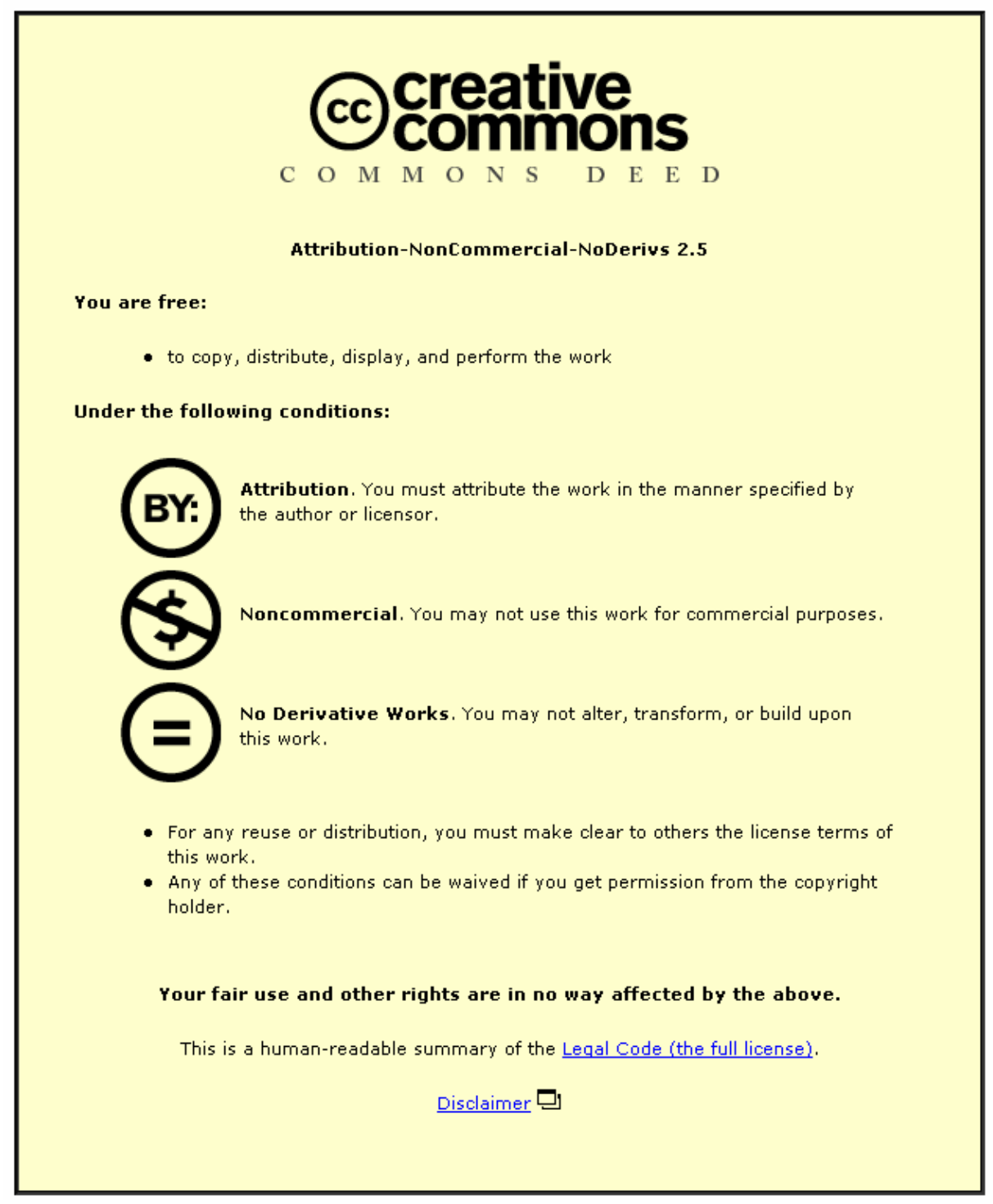

For the full text of this licence, please go to: http://creativecommons.org/licenses/by-nc-nd/2.5/ 


\title{
Effect of Dispersants on the Rheology of Aqueous Silicon Carbide Suspensions
}

\author{
Yongheng Zhang*, a , Jon Binner ${ }^{\#,}$
}

* College of Materials Science and Engineering, Qingdao University of Science and Technology, Qingdao 266042, China

a Key Lab of Rubber-Plastics (QUST), Ministry of Education, Qingdao University of Science and Technology, Qingdao 255042.

\# Institute of Polymer Technology \& Materials Engineering, Loughborough University, Leicestershire, LE11 3TU, UK

\section{Abstract}

The effect of cationic and anionic dispersants on aqueous suspensions of as-received and surface-modified silicon carbide particles has been studied via observation of the rheological behaviour. Only the cationic dispersants were effective for the as-received SiC, with polyethyleneimine being superior to Hyamine 2389 probably as a result of a greater electrosteric interaction. SiC particles modified using $\mathrm{Al}\left(\mathrm{NO}_{3}\right)_{3}$ behaved like alumina and so could be dispersed using the anionic dispersants ammonium polyacrylate and polymethacrylate. Such dispersions displayed no heteroaggregation when alumina was added, although the order of mixing could significantly affect the rheological behavior of the suspension. Nevertheless, the suspensions appeared robust to slight fluctuations in $\mathrm{pH}$. Keywords: A: suspension; A: Rheology; D: SiC 


\section{Introduction}

Achieving adequate dispersion of ceramic powders is important for suspension-based ceramic green forming; it is generally necessary to prepare the suspensions with as high solid content and low viscosity as possible. Due to the wide use of alumina ceramics, the dispersion of these powders into water has been extensively studied and the dispersants used are commonly polyelectrolytes such as polyacrylic acid (PAA), polymethylacrylic acid (PMAA) and their (usually ammonium) salts $[1,2,3,4,5]$. However, there are very few reported papers on the dispersion of silicon carbide, SiC, powders into water.

A small number of researchers have used ammonia or sodium hydroxide solutions to adjust the $\mathrm{pH}$ of their suspensions [6,7,8], whilst Si et al. [9] used tetramethylammonium hydroxide (TMAH). In both cases the aim was to maximise the zeta potential of the SiC particles in aqueous suspension. In contrast, Sano [10] used styrene-maleic acid copolymers, the resulting $33 \mathrm{vol} \%$ solid content suspension exhibited a viscosity of only $190 \mathrm{mPa}$ s at a shear rate of $6.9 \mathrm{~s}^{-1}$, whilst other promising dispersants are the weak cationic polyelectrolytes polyethyleneimine (PEI) and polyvinylimidazole (PVI). The former has been used for the flocculation of silica ${ }^{\S}, \mathrm{SiO}_{2}$, suspensions [11] whilst the latter, which has similar properties to

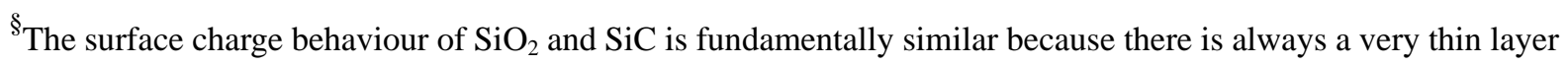
of $\mathrm{SiO}_{2}$ on the surface of $\mathrm{SiC}[12,13,14]$. In both cases, therefore, the zeta potential is negative when the $\mathrm{pH}$ is higher than the point of zero charge (PZC), typically $\mathrm{pH} 3 \pm 1$. The polyelectrolytes adsorb onto the surface of the particles due to the electrostatic attraction force between the particles and the ionised groups on the polymer segments, the level of adsorption also being dependent on the molecular weight of the polymer.
} 
PEI and shows good adsorption onto the surfaces of the particles, has been studied for dispersing SiC powder [15]. However, in neither case was a rheological study of the resulting suspensions reported.

A further complicating factor when producing $\mathrm{SiC}$ ceramics is that sintering additives are usually required to generate liquid phases and hence lower the sintering temperature. The additives commonly used are alumina and yttria, however these have different surface charge behaviours compared to $\mathrm{SiC}$. The $\mathrm{PZC}$ of $\mathrm{SiC}$ lies in the range $\mathrm{pH} 2-4$, depending on the nature of the powder used [16,17], whilst that of $\mathrm{Al}_{2} \mathrm{O}_{3}$ is generally $\mathrm{pH} 8-9[1,2,18]$. Mixing these two powders in aqueous media therefore causes heteroaggregation due to the electrostatic attraction of the differently charged particles.

In order to make nonoxide powders such as $\mathrm{SiC}$ and $\mathrm{Si}_{3} \mathrm{~N}_{4}$ compatible with $\mathrm{Al}_{2} \mathrm{O}_{3}$ in aqueous media, a number of surface modification techniques have been studied. For example, Hruschka et al. [19] has investigated the combined use of $\mathrm{Al}(\mathrm{OH})_{3}$ and citric acid diammonium to modify $\mathrm{Si}_{3} \mathrm{~N}_{4}$ particles in the $\mathrm{pH}$ range 9 - 10.5. Pei et al. [20] and Shih et al. [21] examined the effect of directly coating fine alumina particles onto the $\mathrm{SiC}$ and $\mathrm{Si}_{3} \mathrm{~N}_{4}$ surfaces. In contrast Lidén et al. [22] coated aluminium tri-isopropoxide onto the surface of a SiC powder via mixing the two materials in acetone in a $\mathrm{N}_{2}$ atmosphere; deionized water was then added to react with the alkoxide and the suspension dried to yield an $\mathrm{Al}_{2} \mathrm{O}_{3}$-surface coated powder. A similar method has been studied by Luther [23] to coat $\mathrm{Si}_{3} \mathrm{~N}_{4}$ powder. In previous work by the present authors [24], SiC particles have been modified in-situ using $\mathrm{Al}^{3+}$ complexes in aqueous suspension via additions of $\mathrm{Al}\left(\mathrm{NO}_{3}\right)_{3}$ and control of the $\mathrm{pH}$. The $\mathrm{Al}^{3+}$ formed hydrolyzed complexes that 
adsorbed onto the charged sites on the SiC particle surfaces, as a result the $\mathrm{SiC}$ particles behaved in an alumina-like manner in the approximate $\mathrm{pH}$ range 5 - 8. The modified SiC particles were then further treated with two different polyelectrolytes that sequentially adsorbed onto the particle surfaces yielding a maximum surface charge. As a result of this surface modification process, the $\mathrm{SiC}$ could be co-dispersed with $\mathrm{Al}_{2} \mathrm{O}_{3}$ in aqueous suspensions without heteroaggregation occurring. However, the rheology of the suspensions was not studied.

In the present work, the effect of different dispersants on the rheology of aqueous SiC suspensions has been evaluated for both an as-received SiC powder and the $\mathrm{Al}^{3+}$ complex-based, surface-modified version described above with a view to developing a practical co-dispersion system for $\mathrm{SiC}$ and alumina.

\section{Experimental Materials and Methods}

\section{Materials}

The ceramic powders used were silicon carbide, SiC (Ultrafein; ESK, Kempten, Germany) and aluminium oxide, $\alpha-\mathrm{Al}_{2} \mathrm{O}_{3}$ (99.9\%; Alfa Products, Danvers, MA, USA). Both powders were measured, using a Mastersizer (Malvern Instruments Ltd, Malvern, UK), to have average diameters of $\sim 3 \mu \mathrm{m}$. Aluminium nitrate, $\mathrm{Al}\left(\mathrm{NO}_{3}\right)_{3} \cdot 9 \mathrm{H}_{2} \mathrm{O}$ (99.9\%; Fluka Chemical AG, Buchs, Switzerland) was used for the initial surface modification work. Three chemicals were used as dispersants, viz.: Hyamine 2389 [HY], a 50 wt\% solution of 
methyldodecylbenzyltrimethylammonium chloride and methyldodecylxylenebistrimethylammonium chloride (Merck Chemicals Ltd, Poole, UK); polyethyleneimine [PEI], a $50 \mathrm{wt} \%$ solution with a molecular weight (mw) of 50,000 (Fluka Chemical AG, Buchs, Switzerland); and Dispex A40 [A40], an ammonium polyacrylate solution with a mw of 2500 (Allied Colloids Ltd, Bradford, UK). The latter dispersant was used in combination with KA11, an ammonium polymethacrylate solution with a mw of 10,000 (Allied Colloids Ltd, Bradford, UK). Analytical grade $\mathrm{KNO}_{3}$ powder, $\mathrm{NH}_{4} \mathrm{OH}$ and $\mathrm{HCl}$ solutions (Aldrich Chemicals Ltd, Gillingham, UK) were also used; the water was deionised.

\section{Zeta potential measurements}

The zeta potential of the as-received SiC particles in the presence of the HY, PEI and A40 and SiC particles surface modified with varying amounts of $\mathrm{Al}\left(\mathrm{NO}_{3}\right)_{3}$ in the presence of different concentrations of A40 were measured (Zetasizer4; Malvern Instruments Ltd, Malvern, UK) to evaluate the effects of the dispersants on the surface charges present. The procedure involved preparing 0.3 vol\% suspensions using ultrasonic agitation (200 W; Kerry Ultrasonics Ltd, Herts, UK) for 3 minutes followed by a 15 minute period to allow the suspension to settle. 0.5 $\mathrm{ml}$ aliquots taken from the upper region of the suspension containing the finest particles were then added to extremely clean glass beakers containing $20 \mathrm{ml}$ of $0.01 \mathrm{M} \mathrm{KNO}_{3}$ solution. The $\mathrm{pH}$ values (Jenway 3051; Jenway Co. Ltd., Essex, UK) of the dilute suspensions were adjusted within the range $\sim 2.5$ to 10 using $0.1 / 1 \mathrm{M} \mathrm{HCl}$ or $\mathrm{NaOH}$ solution. Four separate zeta potential measurements were then obtained on each sample to determine the consistency of the results. 


\section{Suspension preparation and viscosity measurements}

The effect of the different dispersants on the rheological behaviour was evaluated by measuring the viscosities of both the as-received $\mathrm{SiC}$ and surface-modified $\mathrm{SiC}$ aqueous suspensions as a function of shear rate using a Visco 88 viscometer with 14, 25 and $30 \mathrm{~mm}$ diameter concentric cylinders (Bohlin UK Ltd, Cirencester, UK). For the as-received SiC, the procedure involved preparing suspensions containing a predetermined amount of powder, water and, separately, the HY, PEI and A40 dispersants; these were mixed by ball milling for 8 hours before the viscosity measurements were made.

The surface modification procedure for the SiC particles has been described in detail elsewhere [24]. Briefly, it involved mixing $\mathrm{Al}\left(\mathrm{NO}_{3}\right)_{3}$ solution into deionised water followed by addition of the $\mathrm{SiC}$ powder and $\mathrm{pH}$ adjustment to 5.8. After stirring for two hours, A40 was added followed by mixing in a ball mill for 4 hours and then KA11 followed by a further 4 hours of ball mixing. The effect of $\mathrm{Al}\left(\mathrm{NO}_{3}\right)_{3}$ concentration on suspension viscosity was investigated using 6.8, 13.2 and $21.3 \mathrm{mg}$ of $\mathrm{Al}\left(\mathrm{NO}_{3}\right)_{3}$ per gram of $\mathrm{SiC}$ (referred to henceforth as $\mathrm{mg} \mathrm{g}^{-1}$ ) with levels of A40 from 0 to $24 \mathrm{mg} \mathrm{g}^{-1}$. Subsequently, the effect of A40 concentration was studied using 2, 6.7 and $10 \mathrm{mg} \mathrm{g}^{-1}$ of A40 at concentrations of KA11 ranging from 0 to 16 $\mathrm{mg} \mathrm{g}^{-1}$. The effect of mixing sequence on viscosity was also investigated by using three experimental procedures: (1) SiC particles initially modified with $\mathrm{Al}\left(\mathrm{NO}_{3}\right)_{3}$, then $\mathrm{A} 40$ added and finally KA11, (2) SiC particles initially modified with $\mathrm{Al}\left(\mathrm{NO}_{3}\right)_{3}$, then $\mathrm{KA} 11$ added and finally A40, (3) $\mathrm{Al}\left(\mathrm{NO}_{3}\right)_{3}, \mathrm{~A} 40$ and $\mathrm{KA} 11$ all added simultaneously to the SiC particle suspension. 
The effect of suspension $\mathrm{pH}$ was investigated by adjusting it to 5.1 or 6.0 using either $\mathrm{HCl}$ or $\mathrm{NH}_{4} \mathrm{OH}$ solution for 32 vol\% solid content suspensions prepared with $13.2 \mathrm{mg} \mathrm{g}^{-1}$ of $\mathrm{Al}\left(\mathrm{NO}_{3}\right)_{3}$ and $14 \mathrm{mg} \mathrm{g}^{-1}$ of A40. Finally, a 32 vol\% suspension made up of equal proportions of SiC and $\mathrm{Al}_{2} \mathrm{O}_{3}$ was prepared using $13.2 \mathrm{mg} \mathrm{g}^{-1}$ of $\mathrm{Al}\left(\mathrm{NO}_{3}\right)_{3}, 6.7 \mathrm{mg} \mathrm{g}^{-1}$ of $\mathrm{A} 40$ and $8 \mathrm{mg} \mathrm{g}^{-1}$ of KA11. The $\mathrm{Al}_{2} \mathrm{O}_{3}$ was added after the $\mathrm{Al}\left(\mathrm{NO}_{3}\right)_{3}$ but before the $\mathrm{A} 40$ to determine the possibility of preparing co-dispersions of $\mathrm{SiC}$ and $\mathrm{Al}_{2} \mathrm{O}_{3}$ using the surface modification process.

\section{Results and Discussion}

\section{Rheology of as-received SiC particle suspensions}

The changes of zeta potential with increasing concentrations of HY, PEI and A40 are shown in figure 1. Since the HY and PEI were both cationic in nature, they carried a positive charge and so could be adsorbed onto the negatively charged SiC particle surfaces by electrostatic attraction. The isoelectric point (IEP) for the PEI occurred at $\sim 3 \mathrm{mg} \mathrm{g}^{-1}$ and its effect on zeta potential was significant for concentrations up to $\sim 7 \mathrm{mg} \mathrm{g}^{-1}$, whilst the $\mathrm{HY}$, being less positive, was less effective. The IEP was reached at $\sim 4 \mathrm{mg} \mathrm{g}^{-1}$ and the zeta potential was lower at any given concentration. Since the A40 was anionic, its effect was to increase the negative zeta potential and the electrostatic interactions will have been repulsive. Similar behaviour was reported by Hruschka et al. [19] for the adsorption of citric acid diammonium onto negatively charged $\mathrm{Si}_{3} \mathrm{~N}_{4}$ particles.

Viscosities for the as-received $\mathrm{SiC}$ suspensions as a function of shear rate and PEI 
concentration are shown in figure 2a and b for solids contents of 40 and 47 vol\% respectively. Figure 2a shows that a maximum occurred at a PEI concentration of $\sim 2.5 \mathrm{mg} \mathrm{g}^{-1}$, matching closely the value for surface charge neutralisation indicated by figure 1 . At concentrations of $\mathrm{PEI} \geq 6.5 \mathrm{mg} \mathrm{g}^{-1}$, when the zeta potential was nearing its maximum positive value, the viscosity was as low as $0.2 \mathrm{~Pa}$ s at $18 \mathrm{~s}^{-1}$, even with a solid content of $40 \mathrm{vol} \%$, showing that the degree of dispersion was high. Note, however, that when the solid contents and PEI concentration were high the suspensions became shear thickening at high shear rates, figure 2b. Since this behaviour was not observed with any of the other dispersants it is not believed to have been an artefact of the measurement system. Rather, it may have been due to the breakdown of the entanglement of the polymer chains, which, at a given shear rate, can result in shear thickening behaviour [25].

Figure 3 shows the viscosities for the as-received $\mathrm{SiC}$ suspensions as a function of shear rate and HY concentration. The suspensions were shear thinning at all shear rates, though the solids content investigated was only $30 \mathrm{vol} \%$, and, at $18 \mathrm{~s}^{-1}$, the viscosity of the suspension was a maximum at an $\mathrm{HY}$ concentration of $1.9 \mathrm{mg} \mathrm{g}^{-1}$. This was about half what would have been expected based on charge neutralisation from figure 1 . There are a number of reasons why this might have occurred. For example, it might be due to the physical nature of the surfactant; it has a long hydrophobic tail with a positive charge at the end that could give rise to a high steric effect. Alternatively, the explanation could simply be that the zeta potential measurements were obtained on low solids content suspensions of fine particles. This could have biased the data if the surface chemistry varied with particle size. Nevertheless, the best dispersion prepared using HY had a viscosity of about 0.6 Pa s at $18 \mathrm{~s}^{-1}$, three times higher than for the PEI 
despite the lower solid content used. Hence the HY was not as effective a dispersant as the PEI for preparing as-received $\mathrm{SiC}$ aqueous suspensions.

The viscosity curves of the suspensions prepared using A40 dispersant are shown in Figure 4. The lowest viscosity achieved was 0.6 Pa s at $18 \mathrm{~s}^{-1}$ for a solid content of 30 vol\%, i.e. similar to that observed for the HY dispersant. The viscosity showed negligible change until the highest level of A40 used, $42 \mathrm{mg} \mathrm{g}^{-1}$. Given that the change in zeta potential with increasing A40 concentration was extremely limited, figure 1, this suggests that saturation absorption was reached at less than $\sim 7 \mathrm{mg} \mathrm{g}^{-1}$. Hence the very limited decrease in viscosity at the higher A40 concentration might be due to the weak depletion effect caused by free A40 in solution.

\section{Rheology of surface-modified SiC particle suspensions}

\subsection{Effect of $\mathrm{Al}\left(\mathrm{NO}_{3}\right)_{3}$ concentration on viscosity}

The viscosity results at $18 \mathrm{~s}^{-1}$ for the surface modified SiC suspensions as a function of A40 content for three different $\mathrm{Al}\left(\mathrm{NO}_{3}\right)_{3}$ concentrations are shown in figure 5a. It can be seen that all the suspensions behaved in a similar manner at low A40 concentrations, the viscosity decreasing with increasing A40 content because of the increased electrosteric force present. However, above about $8 \mathrm{mg} \mathrm{g}^{-1}$ the lowest and highest $\mathrm{Al}\left(\mathrm{NO}_{3}\right)_{3}$ concentration samples displayed a maximum in their viscosities. It is not certain why this behaviour was observed, though a similar phenomenon has been observed before when adding ammonium polyacrylate to alumina suspensions $[26,27]$. Then, it was attributed to the occurrence of different adsorbed configurations of the ammonium polyacrylate at the different concentrations. 
It is known that the configurations of absorbed polyelectrolytes depend on the charge density ratio between the particle surface and polyelectrolyte, and that they affect the interparticle forces present $[1,26]$. A high charge density ratio results in a low-affinity adsorption and hence high interparticle forces whilst a low charge ratio results in the opposite behaviour [1]. In the present work, whilst the charge density of the particle surface will have changed with increasing A40 concentration, as indicated by the different isoelectric points observed in figure $5 \mathrm{~b}$ for each of the 3 suspensions, that of the A40 will have been determined by the level of excess $\mathrm{Al}^{3+}$ species in solution. Hence, the charge density ratio will have been different at different A40 concentrations. As a result of the relatively high ionic strength of the suspension, the effects of any changes in the adsorption configuration on viscosity will have been potentially quite significant. Whilst this can be offered as a potential explanation of the results in figure 5a, a more definitive version will have to await further research.

The lack of a maximum in the curve for the suspension containing $13.2 \mathrm{mg} \mathrm{g}^{-1}$ of $\mathrm{Al}\left(\mathrm{NO}_{3}\right)_{3}$ is assumed to indicate that this was close to the ideal addition level. The hypothesis offered is that there were less excess $\mathrm{Al}^{3+}$ complexes present in the liquid phase and hence the configuration of the A40 did not change as a function of A40 content. It is also interesting to note how similar the zeta potential curve was for this suspension, at A40 concentrations greater than about 5 $\mathrm{mg} \mathrm{g}^{-1}$, compared to that for alumina dispersed with the same ammonium polyacrylate dispersant, figure $5 b$.

2.2 Dispersion via the combination of A40 and KA11 dispersants

Following the above results, the surface modification of the SiC particles was standardised by 
using $13.2 \mathrm{mg} \mathrm{g}^{-1} \mathrm{Al}\left(\mathrm{NO}_{3}\right)_{3}$ for all further suspensions. The effect of varying the levels of the A40 and KA11 dispersants on the dispersion of the SiC particles, and hence on the viscosity, is shown in figure 6 . When the A40 concentration was as low as $2 \mathrm{mg} \mathrm{g}^{-1}$ the $\mathrm{SiC}$ particle surfaces will have only been partially covered by A40 molecules and thus the KA11 will have been able to adsorb onto the remaining uncovered sites on the particles [24]. Although the total adsorption of the two polyelectrolytes was probably relatively low, yielding weak repulsion and hence high viscosities, as expected the viscosity decreased as more of the KA11 adsorbed. At higher concentrations of A40, more of the particle surfaces will have been covered by a layer of short chain ammonium polyacrylate, increasing the degree of negative charge on the surface and so restricting further adsorption of the longer chain KA11 [24]. At the highest A40 level, $10 \mathrm{mg} \mathrm{g}^{-1}$, most of the particle surfaces will have been covered by a layer of the polymer preventing much KA11 from adsorbing. Overall this resulted in a viscosity that was low but changed little with increasing KA11 concentration. At the intermediate A40 concentration of $6.7 \mathrm{mg} \mathrm{g}^{-1}$, the particle surfaces will have been only moderately covered and so the long chain KA11 polymer could still adsorb [24]. The long tail of the latter would be free to extend out into the liquid phase yielding a higher steric force, and hence a lower viscosity, than present with either 2 or $10 \mathrm{mg} \mathrm{g}^{-1}$ of A40, at higher KA11 concentrations.

\subsection{Effect of mixing procedures on viscosity}

The mechanism by which it is believed the $\mathrm{Al}\left(\mathrm{NO}_{3}\right)_{3}$, A40 and KA11 controlled the dispersion of the SiC particles in suspension was discussed in the previous sections; it follows that varying the order of mixing was expected to have a significant effect. To this end, two variations on the original procedure were evaluated; these were outlined in table 1 and the results are shown in 
figure 7. As expected, it may be seen that procedure 3, where the $\mathrm{Al}\left(\mathrm{NO}_{3}\right)_{3}, \mathrm{~A} 40$ and $\mathrm{KA} 11$ were all added simultaneously to the SiC particle suspension, showed the highest resultant viscosity indicating that unless the SiC particles were initially modified via the $\mathrm{Al}^{3+}$ complex mechanism the anionic polyelectrolytes were unable to adsorb onto the particle surface and the resulting behaviour was very similar to that for the as-received $\mathrm{SiC}$ particles with no dispersants added, figures 3 and 4. Once the SiC particles had been modified, it made only a small difference in terms of the resultant viscosity which of the two dispersants was added first, though it was clearly preferable at low shear rates when it was the A40. If the KA11 was added first, flocculation initially occurred and although the subsequent addition of the A40 helped obtain dispersion it was not to the same level.

\subsection{Effect of $\mathrm{pH}$ on viscosity}

All of the work reported above was performed at a pH of 5.8 since previous work had shown this to be the optimal value [24]. In order to understand the effects of slight $\mathrm{pH}$ changes on the rheological behaviour of the $\mathrm{Al}\left(\mathrm{NO}_{3}\right)_{3}-\mathrm{A} 40-\mathrm{KA} 11$ dispersion system, $\mathrm{NH}_{4} \mathrm{OH}$ and $\mathrm{HCl}$ solutions were used to modify the $\mathrm{pH}$ of the dispersion to 5.1 and 6.0 for the suspension prepared using procedure 1 (see table 1 ). The resultant viscosities were observed to be $0.3,0.27$ and 0.34 Pa s respectively at $18 \mathrm{~s}^{-1}$. Despite the slight increases in viscosity when the $\mathrm{pH}$ was changed, the result implies that precise control of the $\mathrm{pH}$ is not essential for this process.

\subsection{Effect of addition of alumina on viscosity}

As indicated earlier, the purpose behind the surface modification of the SiC particles was to 
develop a system that permitted the co-dispersion of $\mathrm{SiC}$ and $\mathrm{Al}_{2} \mathrm{O}_{3}$. To this end, even though such large quantities of alumina would not be used in practice, a suspension containing equal quantities of the two ceramic powders was prepared following procedure 1 (see table 1), with the alumina powder being added after the $\mathrm{Al}\left(\mathrm{NO}_{3}\right)_{3}$ and before the A40 and KA11. The viscosity as a function of shear rate is shown in figure 8 together with a similar curve for an alumina suspension of approximately similar solid content. Although the viscosity of the co-dispersion was slightly higher, probably due to the significant amount of $\mathrm{NO}_{3}{ }^{-}$present, the curves show that the surface modification process can be used to produce a $\mathrm{SiC}-\mathrm{Al}_{2} \mathrm{O}_{3}$ co-dispersion with workable rheological properties.

\section{Conclusions}

The overall aim of this work has been to investigate the potential for achieving stable $\mathrm{SiC}-$ $\mathrm{Al}_{2} \mathrm{O}_{3}$ co-dispersions. As-received $\mathrm{SiC}$ particles may be dispersed using Hyamine 2389 (HY) and polyethyleneimine (PEI), with the latter being the superior dispersing agent as a result of generating a stronger electrosteric interaction. As expected, the anionic dispersant Dispex A40 was not effective in this respect. When the $\mathrm{SiC}$ particles were surface-modified using $\mathrm{Al}\left(\mathrm{NO}_{3}\right)_{3}$, the concentration of the latter was found to be important in that it significantly influenced the rheological behaviour. When the $\mathrm{Al}\left(\mathrm{NO}_{3}\right)_{3}$ level was too low or too high, a maximum was observed in the viscosity / dispersant concentration plots at A40 concentrations $>8 \mathrm{mg} \mathrm{g}^{-1}$, however when $13.2 \mathrm{mgg}^{-1}$ of A40 was used a smooth curve was observed and the zeta potential plot was very similar to that for alumina at A40 concentrations $\geq 5 \mathrm{mg} \mathrm{g}^{-1}$. A combination of A40 and KA11 was found to yield better dispersion. As with the $\mathrm{Al}\left(\mathrm{NO}_{3}\right)_{3}$ results, there was an 
optimum level for both polyelectrolytes. If the initial A40 level was too low or too high it affected the viscosity by restricting the performance of the KA11, which is believed to have provided a strong steric dispersion effect. As a result, the order of mixing the three surfactants was also important; the SiC particles needed to be initially modified with the $\mathrm{Al}\left(\mathrm{NO}_{3}\right)_{3}$, then the A40 added and finally the KA11. However, slight variations in the suspension $\mathrm{pH}$ were found to have little effect on the rheological behaviour. As a result of the surface-modification approach, it has been possible to prepare $\mathrm{SiC}-\mathrm{Al}_{2} \mathrm{O}_{3}$ co-dispersions that display no heteroaggregation.

\section{References}

1 J. Cesarano III and I.A. Aksay, Processing of highly concentrated aqueous $\alpha$-alumina suspensions stabilized with polyelectrolytes, Journal of the American Ceramic Society 71 (12) (1988) 1062-67.

2 J. Cesarano III, I.A. Aksay and A. Bleier, Stability of aqueous $\alpha-\mathrm{Al}_{2} \mathrm{O}_{3}$ suspension with poly(methacrylic acid) polyelectrolyte, Journal of the American Ceramic Society 71 (4) (1988) 250-55.

3 V.A. Hackley, Colloidal processing of silicon nitride with poly(acrylic acid): I, adsorption and electrostatic interactions, Journal of the American Ceramic Society 80 (9) (1997) 2315-25.

4 L. Dupont and A. Foissy, Evaluation of the adsorption trends of a low molecular weight polyelectrolyte with a site-binding model, Colloids and Surfaces. A. Physicochemical and Engineering Aspects, 110 (1996) 235-48. 
5 P.C. Hidber, T.J. Graule, and L.J. Gauckler, Citric acid - a dispersant for aqueous alumina suspensions, Journal of the American Ceramic Society 79 (7) (1996) 1857-67.

6 J.M.F. Ferreira and H.M.M. Diz, Effect of slurry structure on the slip casting of silicon carbide powders, Journal of the European Ceramic Society 10 (1992) 59-64.

7 Y. Hirata, S. Yamada, and Y. Fukushige, Colloidal processing of silicon carbide, Materials Letters 16 (1993) 295-99.

8 D. O’Sullivan, M. Poorteman, P. Descamps, F. Cambier, A. Leriche, and B. Thierry, Optimisation of alumina - silicon carbide dispersions and the fabrication of nanocomposite ceramic materials, Key Engineering Materials 99-100 (1995) 247-56.

9 W. Si, T.J. Graule, F.H. Baader, and L.J. Gauckler, Direct coagulation casting of silicon carbide components, Journal of the American Ceramic Society 82 (5) (1999) 1129-36.

10 S. Sano, T. Banno, M. Maeda, K. Oda, and Y. Shibasaki, Slip casting and sintering of silicon carbide (Part 1), Journal of the Ceramic Society of Japan 104 (10) (1996) 984-88.

11 A. Bleier and E.D. Goddard, Flocculation of aqueous silica suspensions using cationic polyelectrolytes, Colloids and Surfaces 1 (1980) 407-23.

12 J. Binner and Y. Zhang, Characterisation of silicon carbide and silicon powders by XPS and zeta potential measurement, Journal of Materials Science Letters 20 (2) (2001) 123-26.

13 T.N. Taylor, The surface composition of silicon carbide powders and whiskers: an XPS study, Journal of Materials Research 4 (1) (1989) 189-203.

14 M.N. Rahaman, Y. Boiteux, and L.C.D. Jonghe, Surface characterization of silicon nitride and silicon carbide powders, American Ceramic Society Bulletin 65 (8) (1986) 1171-76. 
15 B. Popping, A. Deratani, B. Sebille, N. Desbois, J.M. Lamarche, and A. Foissy, The effects of electrical charge on the adsorption of a weak cationic polyelectrolyte onto silica, silicon carbide and calcium fluoride, Colloids and Surfaces 64 (1992) 125-33.

16 J.H. Adair, B.C. Mutsuddy, and E.J. Drauglis, Stabilization of silicon carbide whisker suspensions: I, Influence of surface oxidation in aqueous suspensions, Advanced Ceramics Materials 3 (3) (1988) 231-34.

17 P.K. Whitman and D.L. Feke, Colloidal characterization of ultrafine silicon carbide and silicon nitride powders, Advanced Ceramics Materials 1 (4) (1986) 366-70.

18 G.A. Parks, The isoelectric points of solid oxides, solid hydroxides, and aqueous hydroxo complex systems, Chemical Reviews 65 (1965) 177-98.

19 M.K.M. Hruschka, W. Si, S. Tosatti, T.J. Graule and L.J. Gauckler, Processing of $\beta$-silicon nitride, alumina, and yttria powder suspensions, Journal of the American Ceramic Society 82 (8) (1999) 2039-43.

20 P.T. Pei, J.F. Kelly, and S.G. Malghan, Interface modification and characterization of silicon carbide platelets coated with alumina particles, Colloids and Surfaces A: Physicochemical and Engineering Aspects 70 (1993) 277-87.

21 W.-H. Shih, D. Kisailus, and W.Y. Shih, Rheology and consolidation of colloidal alumina-coated silicon nitride suspensions, Journal of the American Ceramic Society 79 (5) (1996) 1155-62.

22 E. Lidén, L. Bergström, M. Persson, and R. Carlsson, Surface modification and dispersion of silicon nitride and silicon carbide powders, Journal of the European Ceramic Society 7 (1991) 361-68. 
23 E.P. Luther, F.F. Lange, and D.S. Pearson, Alumina surface modification of silicon nitride for colloidal processing, Journal of the American Ceramic Society 78 (8) (1995) 2009-14.

24 Y. Zhang and J. Binner, In situ surface modification of silicon carbide particles using $\mathrm{Al}^{3+}$ complexes and polyelectrolytes in aqueous suspensions, Journal of the American Ceramic Society 85 (3) (2002) 529-34.

25 Y. Otsubo, Normal stress behavior of highly elastic suspensions, Journal of Colloid and Interface Science 163 (2) (1994) 507-511.

26 J. Davies and J.G.P. Binner, The role of ammonium polyacrylate in dispersing high solids content alumina suspensions, Journal of the European Ceramic Society 20 (2000) 1539-1553.

27 Y. Hirata, A. Nishimoto and Y. Ishihara, Effects of addition of polyacrylic ammonium on colloidal processing of $\alpha$-Alumina, Journal of the Ceramic Society of Japan, International Edition 100 (1992) 972-978. 


\section{Table Captions}

Table 1. Mixing procedures for investigating the effect of the order of surfactant additions.

\section{Figure Captions}

1. Changes in zeta potential with dispersant concentration for as-received SiC suspensions at a pH of 5.8.

2. Viscosity as a function of shear rate and PEI concentrations for a) $40 \mathrm{vol} \%$ and b) $47 \mathrm{vol} \%$ as-received $\mathrm{SiC}$ suspensions at a $\mathrm{pH}$ of 5.8.

3. Viscosity as a function of shear rate and HY concentrations for $30 \mathrm{vol} \%$, as-received SiC suspensions at a $\mathrm{pH}$ of 5.8 .

4. Viscosity as a function of shear rate and A40 concentrations for $30 \mathrm{vol} \%$, as-received SiC suspensions at a $\mathrm{pH}$ of 5.8 .

5. Viscosity (a) and zeta potential (b) as a function of A40 concentration for $\mathrm{SiC}$ suspensions modified with different concentrations of $\mathrm{Al}\left(\mathrm{NO}_{3}\right)_{3}$.

6. Viscosity as a function of KA11 concentration for $\mathrm{Al}\left(\mathrm{NO}_{3}\right)_{3}$ complex-modified $\mathrm{SiC}$ suspensions at different levels of A40.

7. Viscosity of SiC suspensions prepared with different mixing procedures. All suspensions 30 vol\% solids content, $13.2 \mathrm{mg} \mathrm{g}^{-1} \mathrm{Al}\left(\mathrm{NO}_{3}\right)_{3}, 6.7 \mathrm{mg} \mathrm{g}^{-1} \mathrm{~A} 40$ and $8 \mathrm{mgg}^{-1} \mathrm{KA} 11$ at $\mathrm{pH} 5.8$.

8. Viscosity as a function of shear rate for $\mathrm{SiC}-\mathrm{Al}_{2} \mathrm{O}_{3}$ and $\mathrm{Al}_{2} \mathrm{O}_{3}$ suspensions. 


\begin{tabular}{|c|l|}
\hline Procedure & \multicolumn{1}{|c|}{ Description } \\
\hline 1 & SiC particles initially modified with $\mathrm{Al}\left(\mathrm{NO}_{3}\right)_{3}$, then $\mathrm{A} 40$ added and finally KA11 \\
\hline 2 & SiC particles initially modified with $\mathrm{Al}\left(\mathrm{NO}_{3}\right)_{3}$, then $\mathrm{KA} 11$ added and finally A40 \\
\hline 3 & $\mathrm{Al}\left(\mathrm{NO}_{3}\right)_{3}, \mathrm{~A} 40$ and $\mathrm{KA} 11$ all added simultaneously to the SiC particle suspension \\
\hline
\end{tabular}

Table 1. Mixing procedures for investigating the effect of the order of surfactant additions. 


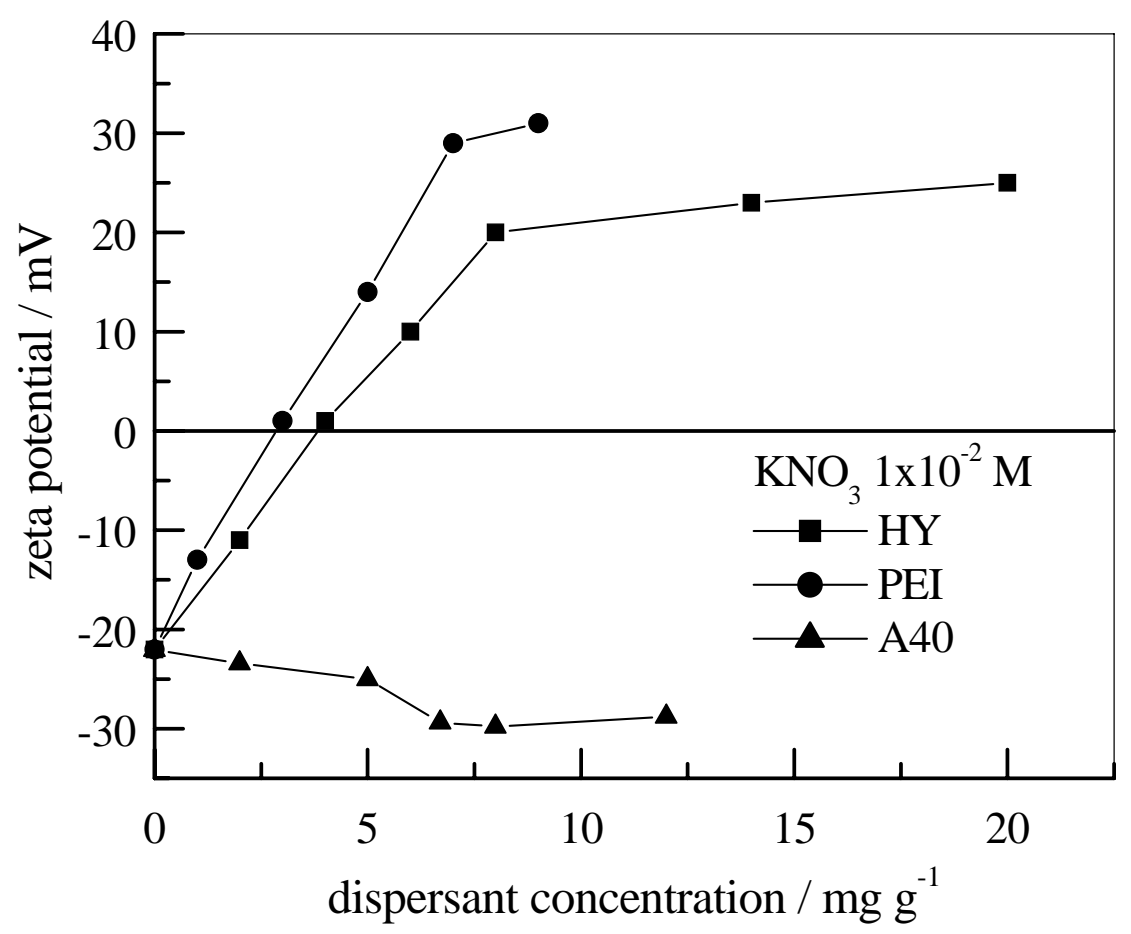

Figure 1. Changes in zeta potential with dispersant concentration for as-received $\mathrm{SiC}$ suspensions at a $\mathrm{pH}$ of 5.8 . 


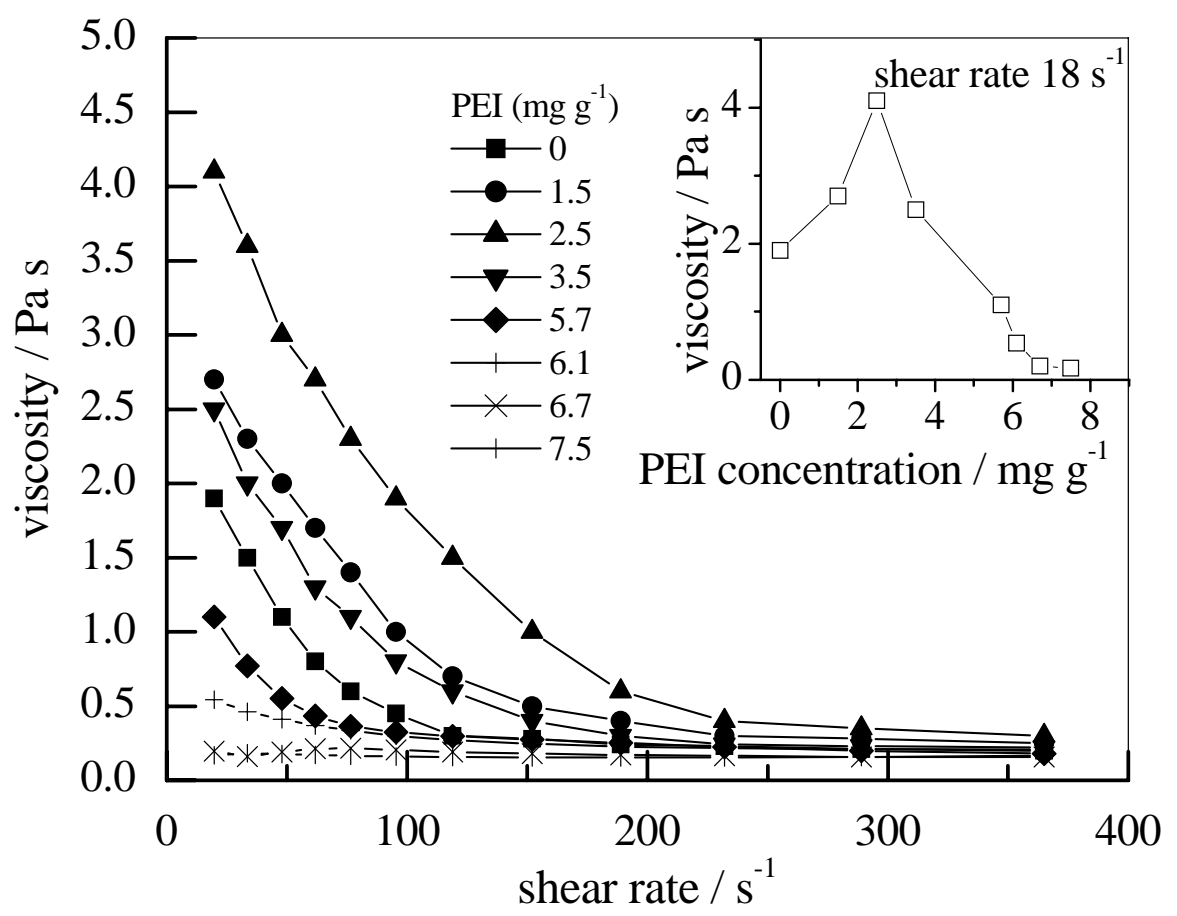

(a)

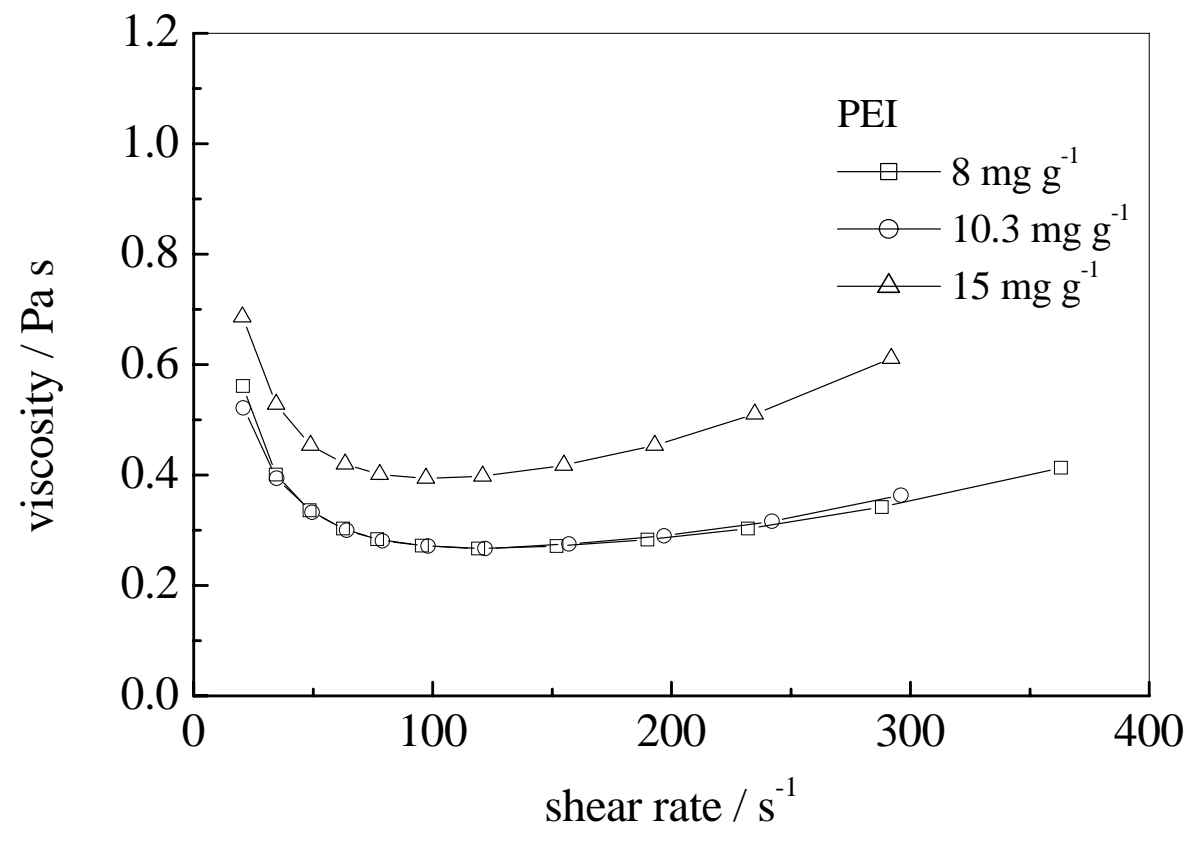

(b)

Figure 2. Viscosity as a function of shear rate and PEI concentrations for a) 40 vol\% and b) 47 vol\% as-received $\mathrm{SiC}$ suspensions at a $\mathrm{pH}$ of 5.8. 


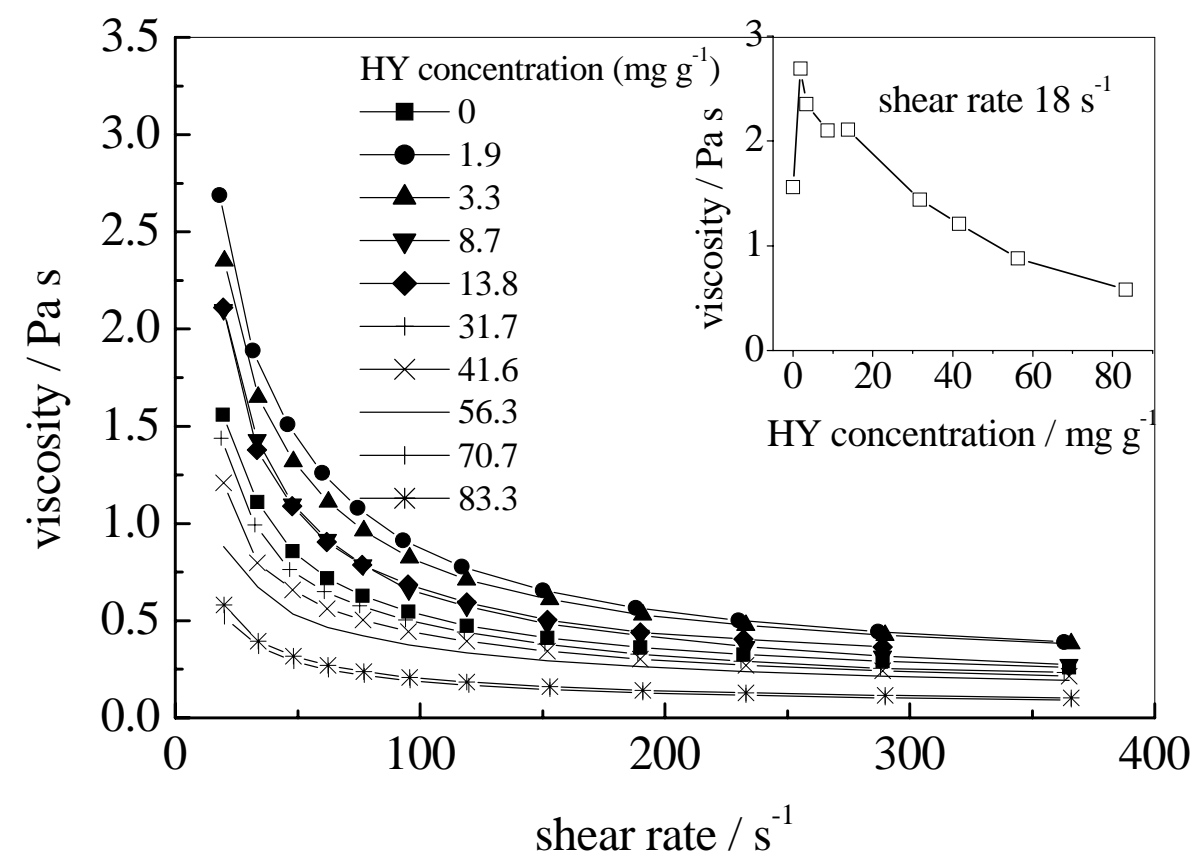

Figure 3. Viscosity as a function of shear rate and HY concentrations for $30 \mathrm{vol} \%$ as-received SiC suspensions at a $\mathrm{pH}$ of 5.8 .

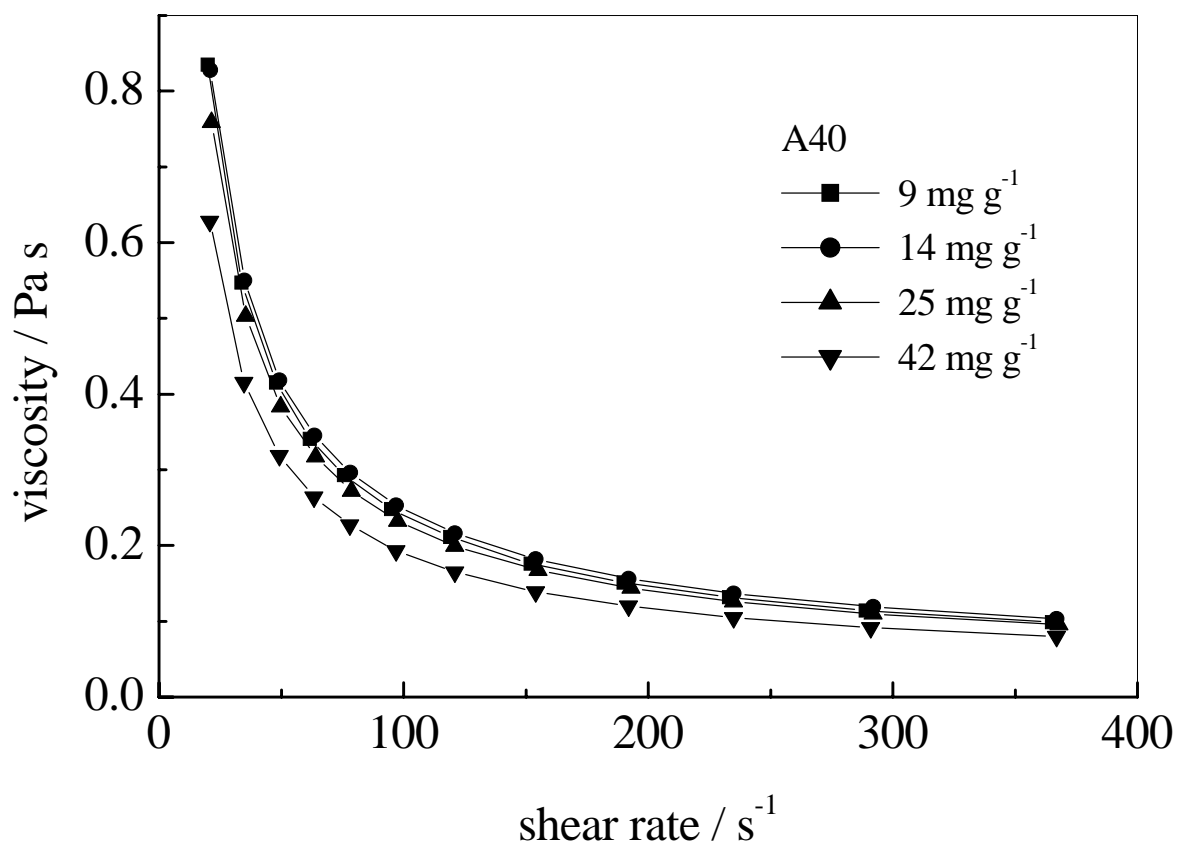

Figure 4. Viscosity as a function of shear rate and A40 concentrations for 30 vol\% as-received SiC suspensions at a $\mathrm{pH}$ of 5.8 . 


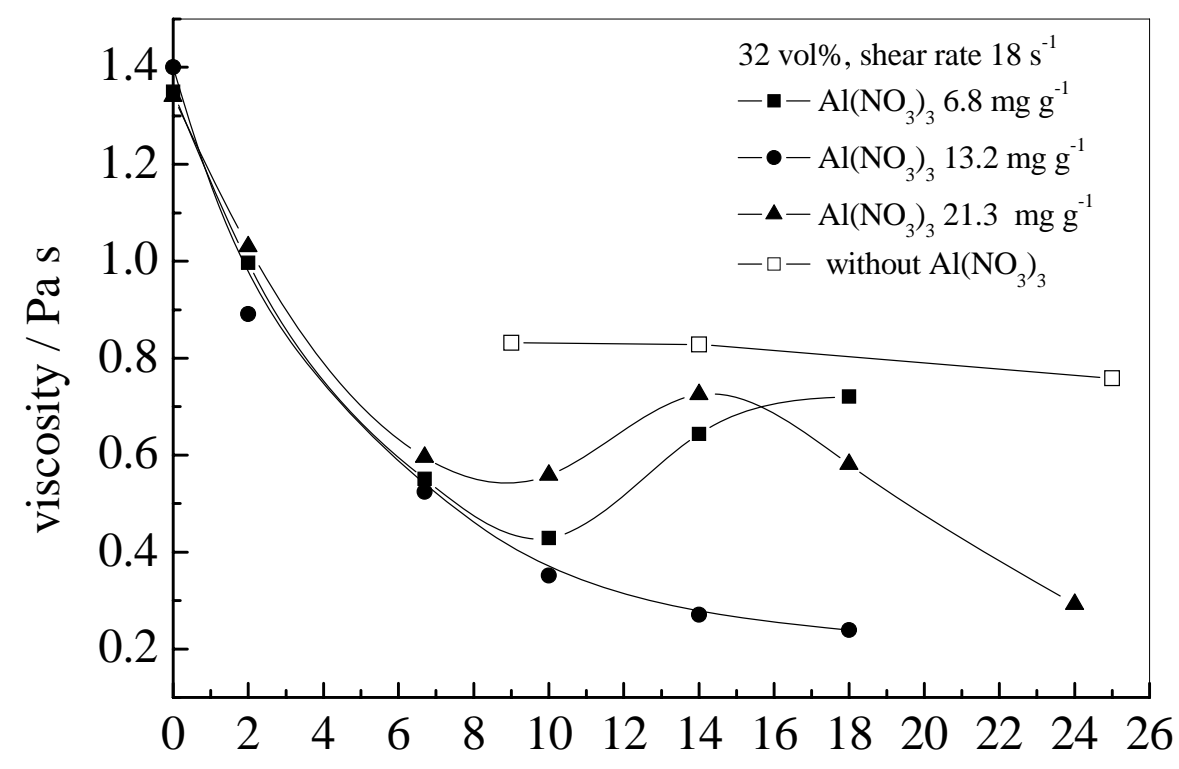

A40 concentration / $\mathrm{mg} \mathrm{g}^{-1}$

(a)

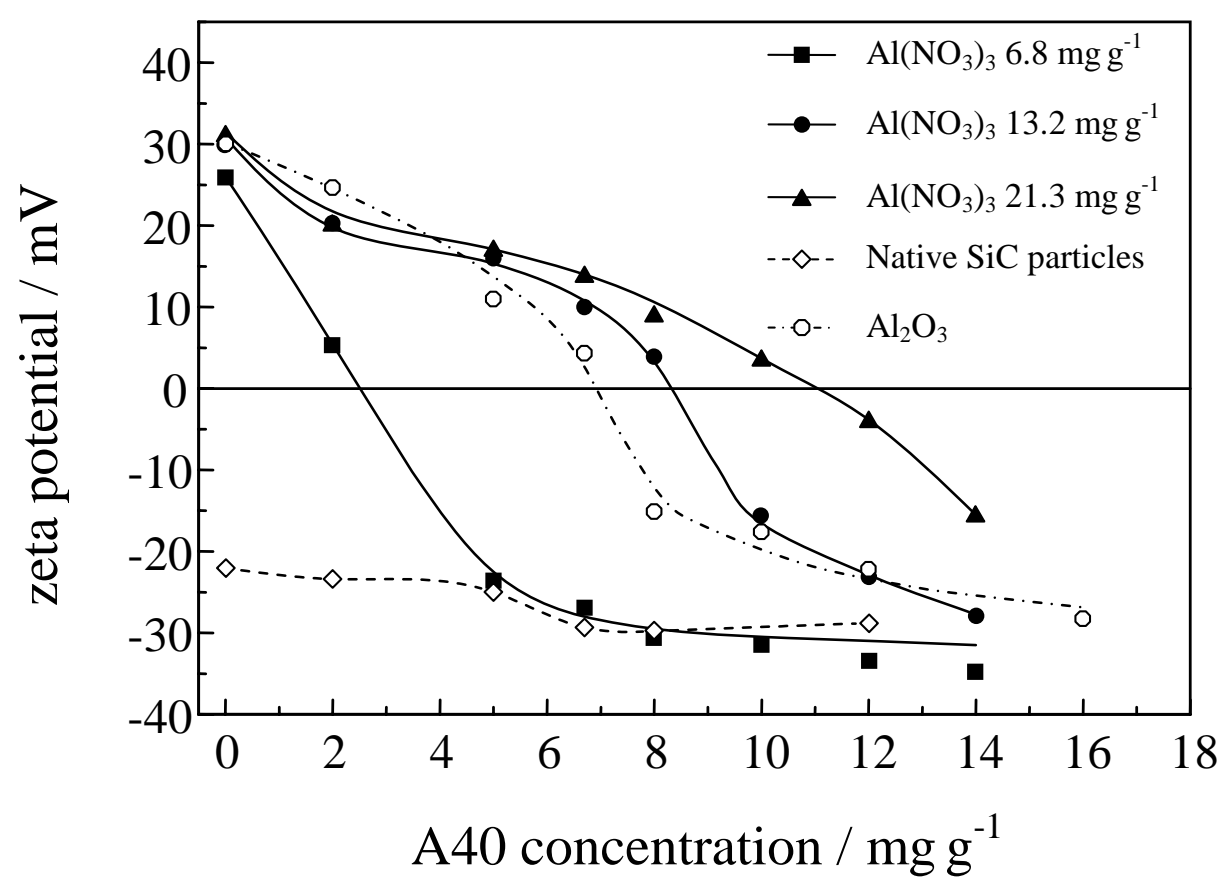

(b)

Figure 5. (a) Viscosity and (b) zeta potential as a function of A40 concentration for $\mathrm{SiC}$ suspensions modified with different concentrations of $\mathrm{Al}\left(\mathrm{NO}_{3}\right)_{3}$. 


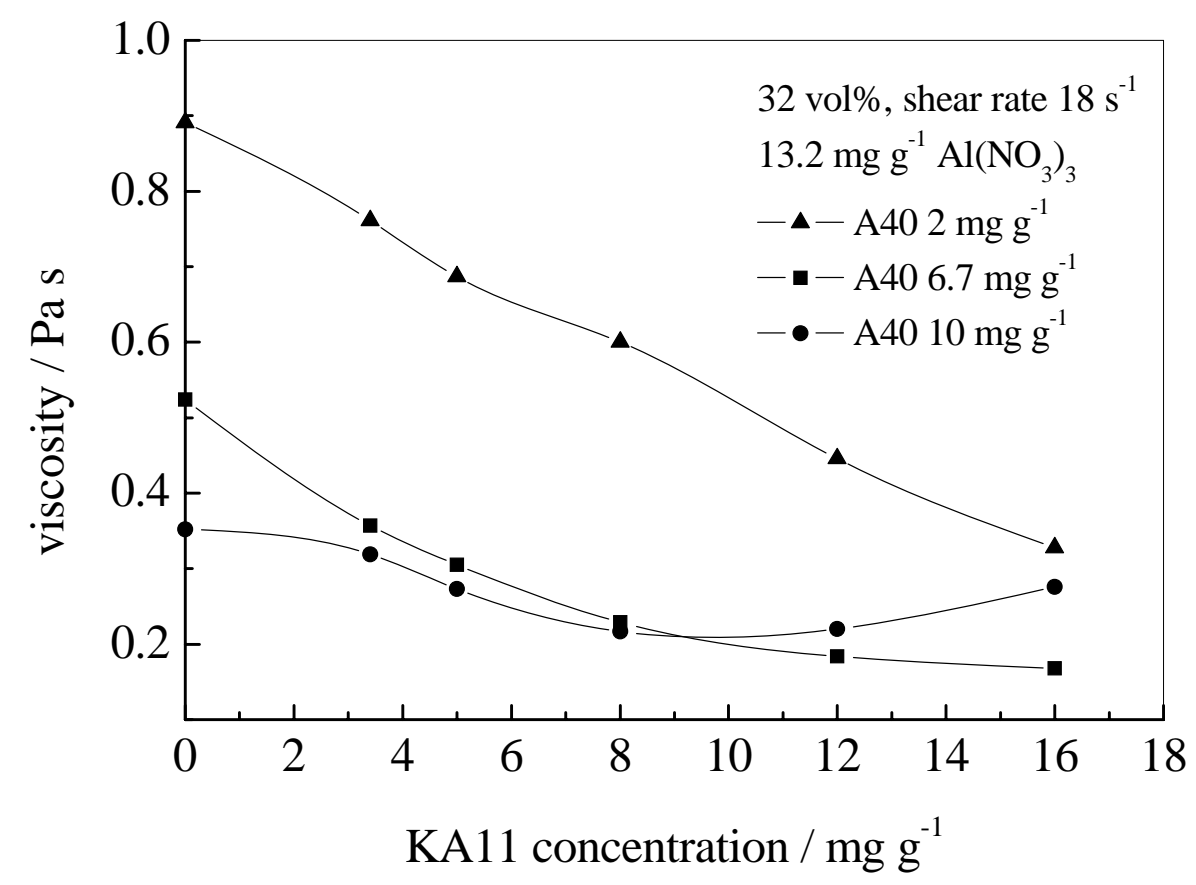

Figure 6. Viscosity as a function of KA11 concentration for $\mathrm{Al}\left(\mathrm{NO}_{3}\right)_{3}$ complex-modified $\mathrm{SiC}$ suspensions at different levels of A40.

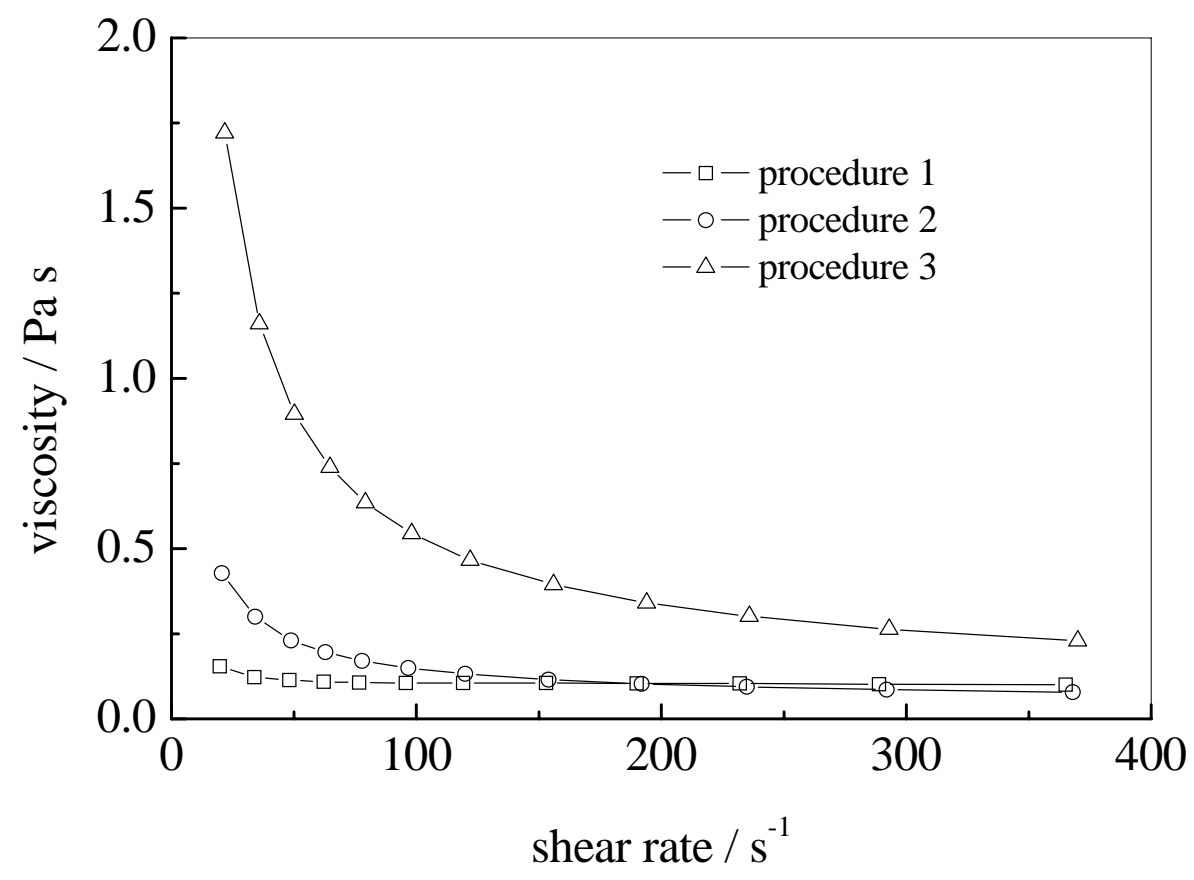

Figure 7. Viscosity of $\mathrm{SiC}$ suspensions prepared with different mixing procedures. All suspensions $30 \mathrm{vol} \%$ solids content, $13.2 \mathrm{mg} \mathrm{g}^{-1} \mathrm{Al}\left(\mathrm{NO}_{3}\right)_{3}, 6.7 \mathrm{mg} \mathrm{g}^{-1} \mathrm{~A} 40$ and $8 \mathrm{mg} \mathrm{g}^{-1} \mathrm{KA} 11$ at $\mathrm{pH}$ 5.8. 


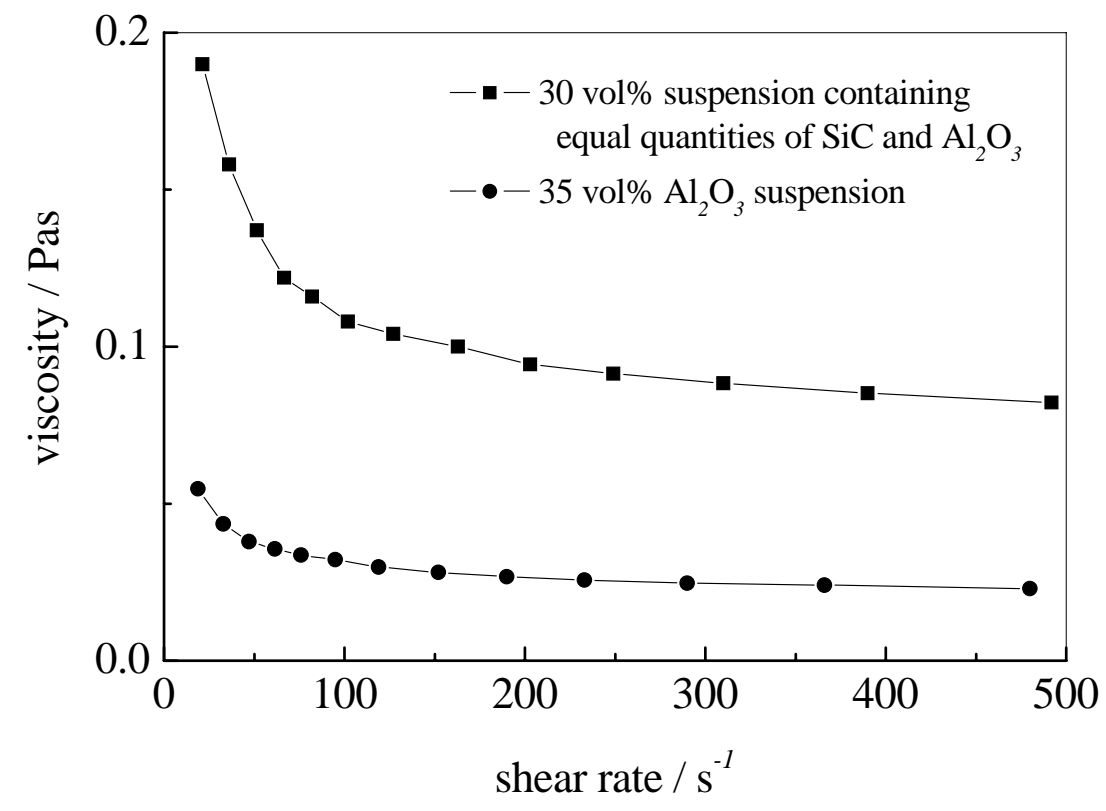

Figure 8. Viscosity as a function of shear rate for $\mathrm{SiC}-\mathrm{Al}_{2} \mathrm{O}_{3}$ and $\mathrm{Al}_{2} \mathrm{O}_{3}$ suspensions. 